\title{
Some Applications of the Gold Activation by Environmental Neutrons
}

\author{
K. Komura, ${ }^{*, a}$ N. K. Ahmed, ${ }^{\text {b }}$ A. H. El-Kamel, ${ }^{\text {c }}$ and A. M. M. Yousef ${ }^{\text {b }}$ \\ ${ }^{a}$ Low Level Radioactivity Laboratory, Kanazawa University, Wake Tatsunokuchi, Ishikawa 923-1224, Japan \\ ${ }^{\mathrm{b}}$ Physics Department, Faculty of Science, South Valley University, Kena, Egypt \\ ${ }^{c}$ Physics Department, Faculty of Science, Assiut University, Assiut, Egypt
}

Received: August 1, 2008; In Final Form: December 20, 2008

\begin{abstract}
The activation of gold by environmental neutrons was used to study the effect of concrete buildings on the neutron flux and to estimate the thermal neutron flux in and around the building of Kinki University Training Reactor. The results showed that three ceilings of $34 \mathrm{~g} \mathrm{~cm}^{-2}$ thickness decrease the fast neutrons to $26 \%$ from its original value. However, the same reinforced concrete decreases the slow flux to only $62 \%$ from its original value. On the other hand, the thermal neutron flux at $283 \mathrm{~m}$ from the reactor center was two times higher than the environmental background. These results can give attention to the effect of concrete walls as a shielding around the reactors, especially those that have been hold near to the living environments.
\end{abstract}

\section{Introduction}

The vertical cut-off of geomagnetic rigidity and the change of geographical latitudes affect the distribution of the secondary cosmic radiation including neutrons. However, at sea level and its vicinity, the measured neutron data are more affected by the meteorological conditions. ${ }^{1,2}$ The primary cosmic ray interacts with all materials to produce secondary cosmic neutrons. The background measurements at sea and land were made up of neutrons produced, attenuated, reflected, and absorbed by air, water, or ground. ${ }^{2}$ The meteorological data includes air pressure, overhead cloud-amounts, wind speed, precipitation, and water contents. This means that the airground boundary effects on the spatial and energy distributions of the neutrons depend greatly upon the type of local surroundings.

The results of altitude dependence measurements of the environmental neutron flux made by Yousef $^{3}$ showed some difference between the measured neutron flux inside and outside the concrete buildings. This difference appeared as a decrease of the measured flux inside the buildings comparing with that outside the buildings at the same altitude and position. The attention was directed to the effect of concrete. An advantage of the experiment is that the composition of the concrete can be taken as approximately that of the earth with constant moisture contents. ${ }^{4}$ Considering the effect of the concrete, this effect was more clearly at the high altitudes than the low altitudes for slow neutron flux.

As one of the most important applications of the gold activation by environmental neutrons is the study of the neutron flux in the environment around the strong neutron sources such as reactors, accelerators, and so on. Around these sources, the neutrons contribute with great part of radiation doses to the workers in these facilities and the other surrounding circumstances.

\section{Experimental technique}

The environmental neutron measurements were carried out indirectly through the radioactivity induced in pure gold by neutron activation. Because of its suitable half-life (2.694 days)

*Corresponding author. E-mail: komura@yu.incl.ne.jp and high cross section ( $98.5 \pm 0.4$ barn) for thermal neutrons, the ${ }^{198} \mathrm{Au}$ was the most convenient neutron detector as a product of ${ }^{197} \mathrm{Au}(\mathrm{n}, \gamma){ }^{198} \mathrm{Au}$ reaction with $100 \%$ abundance. The $\beta$ decay of ${ }^{198} \mathrm{Au}$ occurs with the emission $\gamma$-rays with $411.8 \mathrm{keV}$ $(95.56 \%)$. The $\gamma$-ray measurements were made using an extremely low-background $\gamma$-ray counting system constructed in the tunnel of former Ogoya Copper Mine (270 mwe depth). ${ }^{5}$ After neutron exposure, the targets were wrapped with cadmium sheets and brought back to laboratory as early as possible to start $\gamma$-ray measurements. The $411.8 \mathrm{keV} \gamma$-ray from ${ }^{198} \mathrm{Au}$ was measured to calculate the number of ${ }^{198} \mathrm{Au}$ atoms produced in unit weight of gold and then converted to the neutron flux using the three-dimensional Monte Carlo code MORSE-CG. ${ }^{6}$

\section{Sampling}

To study the effect of concrete buildings on the environmental neutron flux, the experiments were mainly conducted in a 3 -storied concrete building of Low Level Radioactivity Laboratory (LLRL), Kanazawa University. As seen in Figure 1 , data were taken at each floor, as well as the roof of the building. Three targets of $50 \mathrm{~g}$ gold grains inside paraffin of $7.5 \mathrm{~cm}$ thickness were exposed at the first and second floors and the roof of LLRL. In addition, twelve gold targets of $20 \mathrm{~g}$ grains were distributed on the roof and the three floors of the building. Four target sets composed of bare, $\mathrm{Cd}(0.5 \mathrm{~mm}$ thick) covered, and paraffin ( $7.5 \mathrm{~cm}$ thick) covered were exposed at every point. Three kinds of the targets in each set were placed at

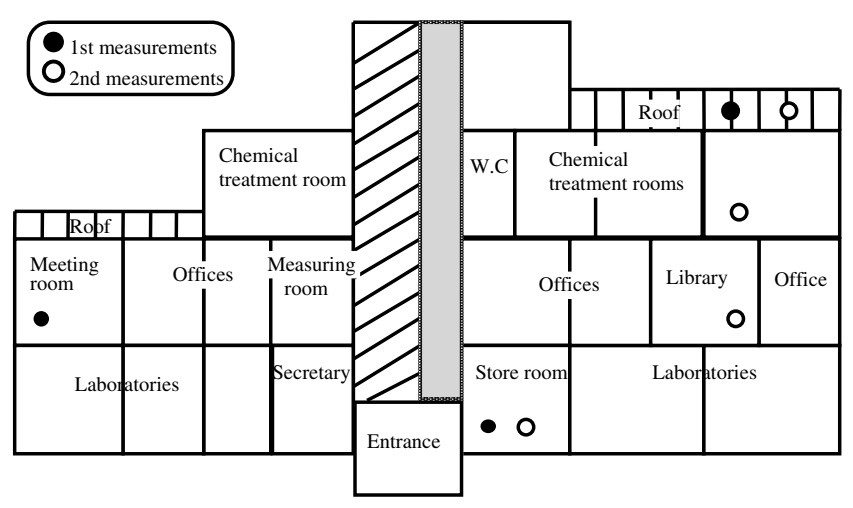

Figure 1. Target set positions at LLRL. 
least $80 \mathrm{~cm}$ apart from each other to avoid interaction. The black circles in Figure 1 show the position of the targets in the first experiment, while the open circles represent the second experiment. As a point of notification, the second floor-target has only one concrete ceiling in the first measurements as shown in Figure 1. The thickness of every reinforced-concrete layer was estimated to be about $34 \mathrm{~g} \mathrm{~cm}^{-2}$.

On the other hand, at Kinki University Training Reactor (UTR-Kinki), 25 gold sheet targets were divided to 5 groups to estimate the thermal neutron flux inside and around the reactor (Figure 2). The first group (A1-A4) consisted of 4 targets, which were exposed inside the reactor body for one-hour operation. Two of these targets were placed in the core of the reactor and the other two were placed at $20 \mathrm{~cm}$ above the core. One target at each place was covered with a $0.5 \mathrm{~mm} \mathrm{Cd}$ sheet to estimate the $\mathrm{Cd}$ ratio in the high intensity flux. The targets were cooled for 17 days before $\gamma$-ray measurement because of their high radioactivity level. The targets of the second group $(3,6,8$, and 11) were distributed inside the reactor room at four different distances from the reactor center. This group was exposed for one hour only during the reactor operation to estimate the thermal neutron flux around the reactor body during the operation. After $24 \mathrm{~h}$ cooling, the $\gamma$-ray of targets was measured by Ge detectors. The targets of the third group were exposed at the same points of the second group for one week to evaluate the average neutron flux over one week operation. This group consisted of four bare targets $(4,7,9$, and 12) in addition to two targets with $\mathrm{Cd}$ cover (5 and 10). The other five gold targets were distributed inside the reactor building to represent the fourth group (13-17). This group was placed to evaluate the intensity of the thermal neutron flux with which the workers are exposed for one week. The last group consisted of 6 targets (18-23), which were distributed outside the reactor building until $283 \mathrm{~m}$ distance to estimate the thermal neutron flux in the reactor environment and to evaluate the runaway neutrons from the reactor to the surrounding environ-

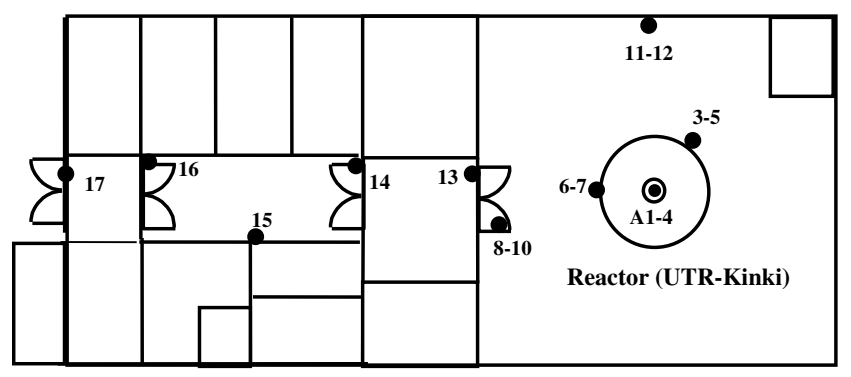

Figure 2. Target set positions at UTR-Kinki. ment. Two of these targets were placed together at the far point. This group was exposed for one week, except for one of the two targets, which was left for one-month exposure to compare with the other target.

All targets were wrapped in $\mathrm{Cd}$ sheets during the cooling time. The short exposure and cooling times were corrected during the calculations of the production of gold atoms $(N)$ using the known equation 1 .

$$
N=\frac{C}{\varepsilon} \frac{1}{1-\exp \left(-\lambda t_{\mathrm{R}}\right)} \frac{1}{\exp \left(-\lambda t_{\mathrm{D}}\right)} \frac{1}{1-\exp \left(-\lambda t_{\mathrm{C}}\right)},
$$

$$
A=\lambda N
$$

where $A$ is the reaction rate of ${ }^{197} \mathrm{Au}(\mathrm{n}, \gamma){ }^{198} \mathrm{Au}, \lambda$ is the decay constant of ${ }^{198} \mathrm{Au}, C$ is the peak count, $\varepsilon$ is the peak efficiency, $t_{\mathrm{R}}$ is the irradiation (exposure) time, $t_{\mathrm{D}}$ is the decay (cooling) time before counting, and $t_{\mathrm{C}}$ is the counting (measuring) time.

\section{Results and discussion}

4.1. Influence of concrete buildings on the environmental neutron flux. Tables 1 and 2 and Figure 3 depict the results of the concrete effect experiments at LLRL. The effect of reinforced concrete is clearly observed from these results. The neutron fluxes were gradually decreased from the roof to the first floor exponentially. The fast neutron flux at the first floor showed $36 \%$ and $26 \%$ from its values at the roof in the first and second experiments, respectively. As a comprehensive estimation, the second experiment is the more interesting for discussion. Although in the fast neutrons measurement, the reduction ratio of $3^{\text {rd }}$ floor / roof and $1^{\text {st }}$ floor $/ 2^{\text {nd }}$ floor was constant, about $13 \%$, this ratio increased to $47 \%$ for $2^{\text {nd }}$ floor/ $3^{\text {rd }}$ floor. The cause of this high reduction is due to the thermalization of the fast neutron by the interaction or scattering with the components of the library, such as aluminum shelves, books, and so on, where the targets were placed. Cadmium measurements have a similar behavior like the fast neutrons

TABLE 1: Fast neutron flux measured with paraffin absorber

\begin{tabular}{cccc}
\hline $\begin{array}{c}\text { Exposure } \\
\text { elevation }\end{array}$ & $\begin{array}{c}{ }^{198} \mathrm{Au} \\
(\text { atoms } / \mathrm{g})\end{array}$ & $\begin{array}{c}\text { Neutron flux } \\
\left(10^{-3} \mathrm{n} \mathrm{cm}^{-2} \mathrm{~s}^{-1}\right)\end{array}$ & $\begin{array}{c}\text { Relative } \\
\text { to roof }\end{array}$ \\
\hline Roof & $75.7 \pm 10.5$ & $1.95 \pm 0.27$ & 1.00 \\
2nd floor & $57.5 \pm 10.6$ & $1.48 \pm 0.27$ & 0.76 \\
1st floor & $27.2 \pm 7.0$ & $0.70 \pm 0.18$ & 0.36 \\
\hline
\end{tabular}

\begin{tabular}{|c|c|c|c|c|c|}
\hline Exposure Condition & Exposure elevation & ${ }^{198} \mathrm{Au}($ atoms/g) & $\begin{array}{l}\text { Neutron flux } \\
\left(10^{-3} \mathrm{n} \mathrm{cm}^{-2} \mathrm{~s}^{-1}\right)\end{array}$ & Reduction ratio & Cd ratio \\
\hline Slow & Roof & $51.6 \pm$ & $7.70 \pm 1.24$ & 1.00 & \\
\hline neutron & 3rd floor & $41.5 \pm 9.6$ & $6.20 \pm 1.43$ & 0.81 & \\
\hline \multirow[t]{2}{*}{ (Bare) } & 2nd floor & $34.9 \pm 10.1$ & $5.20 \pm 1.50$ & 0.68 & \\
\hline & 1st floor & $32.4 \pm 7.4$ & $4.80 \pm 1.10$ & 0.62 & \\
\hline \multirow{4}{*}{$\begin{array}{l}\text { Fast } \\
\text { neutron } \\
\text { (Paraffin covered) }\end{array}$} & Roof & $102 \pm 16.2$ & $1.97 \pm 0.31$ & 1.00 & \\
\hline & 3rd floor & $88.4 \pm 14.6$ & $1.70 \pm 0.28$ & 0.86 & \\
\hline & 2nd floor & $39.9 \pm 8.9$ & $0.77 \pm 0.17$ & 0.39 & \\
\hline & 1st floor & $26.2 \pm$ & $0.51 \pm 0.15$ & 0.26 & \\
\hline \multirow{4}{*}{$\begin{array}{l}\text { Cadmium } \\
\text { measurement } \\
(\text { Cd covered })\end{array}$} & Roof & $15.1 \pm$ & $3.20 \pm 1.00$ & 1.00 & $3.4 \pm 1.2$ \\
\hline & 3rd floor & $10.6 \pm 4.1$ & $2.30 \pm 0.88$ & 0.72 & $3.9 \pm 1.7$ \\
\hline & 2nd floor & $5.74 \pm$ & $1.40 \pm 0.73$ & 0.44 & $6.1 \pm 4.0$ \\
\hline & 1st floor & $3.46 \pm$ & $0.75 \pm 0.67$ & 0.23 & $9.4 \pm 8.6$ \\
\hline
\end{tabular}

TABLE 2: Environmental neutron fluxes measured with bare state, with paraffin, and Cd covered at LLRL building 


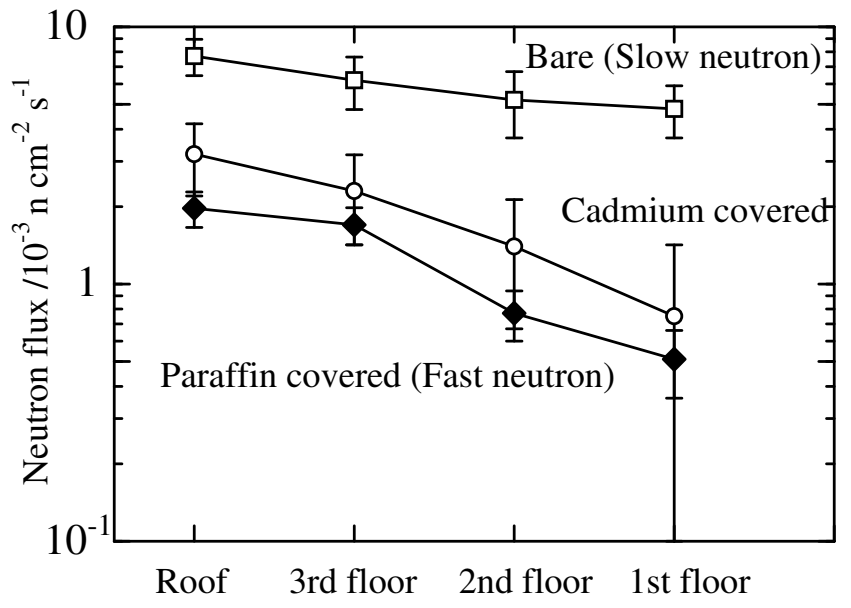

Figure 3. Slow neutron, fast neutron and Cd covered flux at LLRL.

because its value depends mainly on the epithermal flux. On the other hand, the slow neutron flux showed a different behavior. The reduction ratio of $3^{\text {rd }}$ floor/roof was about $19 \%$ and $13 \%$ for $2^{\text {nd }}$ floor $/ 3^{\text {rd }}$ floor, respectively. This ratio decreased to $6 \%$ for $2^{\text {nd }}$ floor $/ 1^{\text {st }}$ floor. The reduction at the third floor came from the concrete effect, whereas at the second and first floors, the absorbed slow neutron flux by concrete is compensated by the thermalization of the high energy neutron flux by the concrete and the other components such as furniture of the building.

The Cd ratio increased gradually from 3.4 at the roof to 9.4 at the first floor, which means that the thermal neutrons are the most predominant than the epithermal neutrons at lower floors. This effect is a result of the thermalization of fast neutrons by the concrete. From these results, it is evident that the concrete is an effective shield for the high-energy neutrons. Three ceilings of $34 \mathrm{~g} \mathrm{~cm}^{-2}$ thickness decreased the flux to $26 \%$ from its original value. However, the same reinforced concrete decreased the slow flux to only $62 \%$ from its original value. These results can give attention to the effect of concrete walls as a shielding around the reactors, especially those that have been hold near to the living environments.

4.2. Estimation of the thermal neutron flux around the Kinki University Reactor. The thermal neutron flux intensity was estimated inside and around the research reactor of Kinki University. The neutron source for starting the reactor is $\mathrm{Pu}-$ Be $(37 \mathrm{GBq})$. The estimated thermal flux at the core of the reactor is $1.2 \times 10^{7} \mathrm{n} \mathrm{cm}^{-2} \mathrm{~s}^{-1}$ and $1.2 \times 10^{5} \mathrm{n} \mathrm{cm}^{-2} \mathrm{~s}^{-1}$ at $20 \mathrm{~cm}$ over the core. On the other hand, the fast neutron flux is $1.3 \times$ $10^{6} \mathrm{n} \mathrm{cm}^{-2} \mathrm{~s}^{-1}$ at the core. According to Prof. Morishima, Cd ratio is estimated to be 5-7 at the core of the reactor. Table 3 shows the results of one-hour exposure targets. The thermal neutron flux at the core of the reactor is $1.24 \times 10^{7} \mathrm{n} \mathrm{cm}^{-2} \mathrm{~s}^{-1}$ and $5.52 \times 10^{5} \mathrm{n} \mathrm{cm}^{-2} \mathrm{~s}^{-1}$ at $20 \mathrm{~cm}$ above the core. The Cd ratio at the two points is 13.4 and 13.6, respectively. These values are about 2 times higher than the official value. The large values of the present data may be caused by the thick $(0.5 \mathrm{~mm})$ $\mathrm{Cd}$ sheet used for covering the gold target or the target position was higher than that of the bare gold experiment. The epithermal neutrons are reflected and moderated from the fast neutron by the components of the reactor or the moderator. The results around the reactor body showed no clear relation between the neutron flux and the distance from the reactor. This is due to the target position in respect to the neutron source. The targets $3-5$ were placed at $3.1 \mathrm{~m}$ over the reactor. The others were set beside the wall of the reactor body $(6,7)$ or steel door $(8-10)$ or the concrete outer wall $(11,12)$. So, the adjacent material may have some effect on the neutron flux. This effect is more clearly at $5.7 \mathrm{~m}$ where the targets number $8-10$ were stock to steel door. The thermal neutron production over steel bodies is about 11 times higher than the environmental background. ${ }^{7}$ This is due to the marked rises of the flux at that point. The average thermal flux inside the reactor room was about $77.6 \pm$ $3.5 \mathrm{n} \mathrm{cm}^{-2} \mathrm{~s}^{-1}$ over the reactor and on an average $15.2 \pm 2.3 \mathrm{n}$ $\mathrm{cm}^{-2} \mathrm{~s}^{-1}$ around the reactor room.

Table 4 shows that the thermal neutron flux measured for one week at the same points has the same behavior except that its intensity was distributed over one week exposure. This means that the measured results for one hour are correct. The average of the thermal neutron flux over one week decreased to $(3.35 \pm 0.18) \mathrm{n} \mathrm{cm}^{-2} \mathrm{~s}^{-1}$ and $(0.68 \pm 0.16) \mathrm{n} \mathrm{cm}^{-2} \mathrm{~s}^{-1}$ over and around the reactor, respectively. These results show that the exposure for one week decreased the average flux intensity to $4.3 \%$ and $4.5 \%$ over and around the reactor, respectively, comparing with its value during the operation. The $\mathrm{Cd}$ ratios at 3.1 $\mathrm{m}$ and at $5.7 \mathrm{~m}$ were 8.2 and 8.4, respectively. Comparing these ratios with those obtained inside the reactor body, it is shown that the Cd-shield is more effective at high neutron flux.

The thermal neutron flux distribution inside the reactor room is plotted together with the flux inside the building in Figure 4 to show the variation of the intensity with the distance from the reactor center. This figure shows obviously that the intensity of the thermal neutron flux decreases exponentially with the distance from the reactor. These results indicate that the thermal neutron flux inside the control room, where the workers spend most of the time during the operation of the reactor, was about $(0.41 \pm 0.04) \mathrm{n} \mathrm{cm}^{-2} \mathrm{~s}^{-1}$. This value was measured by targets number 13 . The average of the corresponding values in the hall was about $(0.08 \pm 0.04) \mathrm{n} \mathrm{cm}^{-2} \mathrm{~s}^{-1}$. This value decreased to $(0.034 \pm 0.008) \mathrm{n} \mathrm{cm}^{-2} \mathrm{~s}^{-1}$ at the entrance of the building.

Figure 4 shows also that the thermal neutron flux decreases gradually with the distance outside the reactor building, but the flux at $283 \mathrm{~m}$ is still higher than the environmental background

TABLE 3: Neutron flux measured for one-hour operation of the UTR-Kinki reactor

\begin{tabular}{|c|c|c|c|c|c|}
\hline Target No. & Condition & $\begin{array}{l}\text { Distance from } \\
\text { the reactor center } \\
(\mathrm{m})\end{array}$ & $\begin{array}{c}{ }^{198} \mathrm{Au} \\
\text { (atoms/g) }\end{array}$ & $\begin{array}{l}\text { Thermal neutro flux } \\
\qquad\left(\mathrm{n} \mathrm{cm}^{-2} \mathrm{~s}^{-1}\right)\end{array}$ & Cd ratio \\
\hline \multicolumn{6}{|c|}{ Inside the reactor } \\
\hline A1 & Bare & 0 & $1.10 \times 10^{11}$ & $1.24 \times 10^{7}$ & \\
\hline A2 & Bare & 0.2 & $4.90 \times 10^{9}$ & $5.52 \times 10^{5}$ & \\
\hline A3 & Cd covered & 0 & $8.20 \times 10^{9}$ & $1.78 \times 10^{6}$ & 13.4 \\
\hline A4 & Cd covered & 0.2 & $3.60 \times 10^{8}$ & $7.81 \times 10^{4}$ & 13.6 \\
\hline \multicolumn{6}{|c|}{ Inside the reactor room } \\
\hline 6 & Bare & 1.9 & $1.18 \times 10^{5} \pm 1.5 \times 10^{4}$ & $13.3 \pm 1.6$ & \\
\hline 3 & Bare & 3.1 & $6.89 \times 10^{5} \pm 3.1 \times 10^{4}$ & $77.6 \pm 3.5$ & \\
\hline 11 & Bare & 5.2 & $1.30 \times 10^{5} \pm 1.2 \times 10^{4}$ & $14.6 \pm 1.3$ & \\
\hline 8 & Bare & 5.7 & $1.58 \times 10^{5} \pm 1.6 \times 10^{4}$ & $17.8 \pm 1.8$ & \\
\hline
\end{tabular}


TABLE 4: Neutron fluxes inside and around the reactor room

\begin{tabular}{|c|c|c|c|c|c|}
\hline Target No. & Condition & $\begin{array}{l}\text { Distance from } \\
\text { the reactor center } \\
(\mathrm{m})\end{array}$ & $\begin{array}{l}{ }^{198} \mathrm{Au} \\
\text { (atoms/g) }\end{array}$ & $\begin{array}{l}\text { Thermal neutron flux } \\
\qquad\left(\mathrm{n} \mathrm{cm}^{-2} \mathrm{~s}^{-1}\right)\end{array}$ & Cd ratio \\
\hline \multicolumn{6}{|c|}{ Inside the reactor room } \\
\hline 7 & Bare & 1.9 & $4.85 \mathrm{E}+03 \pm 5.6 \mathrm{E}+02$ & $5.47 \mathrm{E}-01 \pm 6.3 \mathrm{E}-02$ & \\
\hline 4 & Bare & 3.1 & $2.97 \mathrm{E}+04 \pm 1.6 \mathrm{E}+03$ & $3.35 \mathrm{E}+00 \pm 1.8 \mathrm{E}-01$ & \\
\hline 12 & Bare & 5.2 & $5.58 \mathrm{E}+03 \pm 3.5 \mathrm{E}+02$ & $6.29 \mathrm{E}-01 \pm 4.0 \mathrm{E}-02$ & \\
\hline 9 & Bare & 5.7 & $7.63 \mathrm{E}+03 \pm 5.9 \mathrm{E}+02$ & $8.60 \mathrm{E}-01 \pm 6.6 \mathrm{E}-02$ & \\
\hline 5 & Cd covered & 3.1 & $3.64 \mathrm{E}+03 \pm 2.0 \mathrm{E}+02$ & $7.90 \mathrm{E}-01 \pm 4.4 \mathrm{E}-02$ & $8.2 \pm 0.6$ \\
\hline 10 & Cd covered & 5.7 & $9.07 \mathrm{E}+02 \pm 1.5 \mathrm{E}+02$ & $1.97 \mathrm{E}-01 \pm 3.2 \mathrm{E}-02$ & $8.4 \pm 1.5$ \\
\hline \multicolumn{6}{|c|}{ Inside the reactor building } \\
\hline 13 & Bare & 6 & $3.66 \mathrm{E}+03 \pm 3.5 \mathrm{E}+02$ & $4.12 \mathrm{E}-01 \pm 4.0 \mathrm{E}-02$ & \\
\hline 14 & Bare & 9.7 & $8.96 \mathrm{E}+02 \pm 1.2 \mathrm{E}+02$ & $1.01 \mathrm{E}-01 \pm 1.4 \mathrm{E}-02$ & \\
\hline 15 & Bare & 12.6 & $9.05 \mathrm{E}+02 \pm 1.4 \mathrm{E}+02$ & $1.02 \mathrm{E}-01 \pm 1.5 \mathrm{E}-02$ & \\
\hline 16 & Bare & 15.7 & $3.60 \mathrm{E}+02 \pm 6.8 \mathrm{E}+01$ & $4.10 \mathrm{E}-02 \pm 7.7 \mathrm{E}-03$ & \\
\hline 17 & Bare & 17.6 & $3.04 \mathrm{E}+02 \pm 7.3 \mathrm{E}+01$ & $3.40 \mathrm{E}-02 \pm 8.2 \mathrm{E}-03$ & \\
\hline \multicolumn{6}{|c|}{ Outside the reactor building } \\
\hline 19 & Bare & 12 & $1.65 \mathrm{E}+02 \pm 3.7 \mathrm{E}+01$ & $1.86 \mathrm{E}-02 \pm 4.1 \mathrm{E}-03$ & \\
\hline 20 & Bare & 40 & $1.89 \mathrm{E}+02 \pm 2.5 \mathrm{E}+01$ & $2.13 \mathrm{E}-02 \pm 2.9 \mathrm{E}-03$ & \\
\hline 18 & Bare & 70 & $2.17 \mathrm{E}+02 \pm 3.8 \mathrm{E}+01$ & $2.45 \mathrm{E}-02 \pm 4.3 \mathrm{E}-03$ & \\
\hline 21 & Bare & 140 & $8.69 \mathrm{E}+01 \pm 2.3 \mathrm{E}+01$ & $9.79 \mathrm{E}-03 \pm 2.6 \mathrm{E}-03$ & \\
\hline 23 & Bare & 283 & $1.42 \mathrm{E}+02 \pm 1.5 \mathrm{E}+01$ & $1.60 \mathrm{E}-02 \pm 1.6 \mathrm{E}-03$ & \\
\hline 22 & Bare & 283 & $1.37 \mathrm{E}+02 \pm 2.3 \mathrm{E}+01$ & $1.54 \mathrm{E}-02 \pm 2.6 \mathrm{E}-03$ & \\
\hline
\end{tabular}

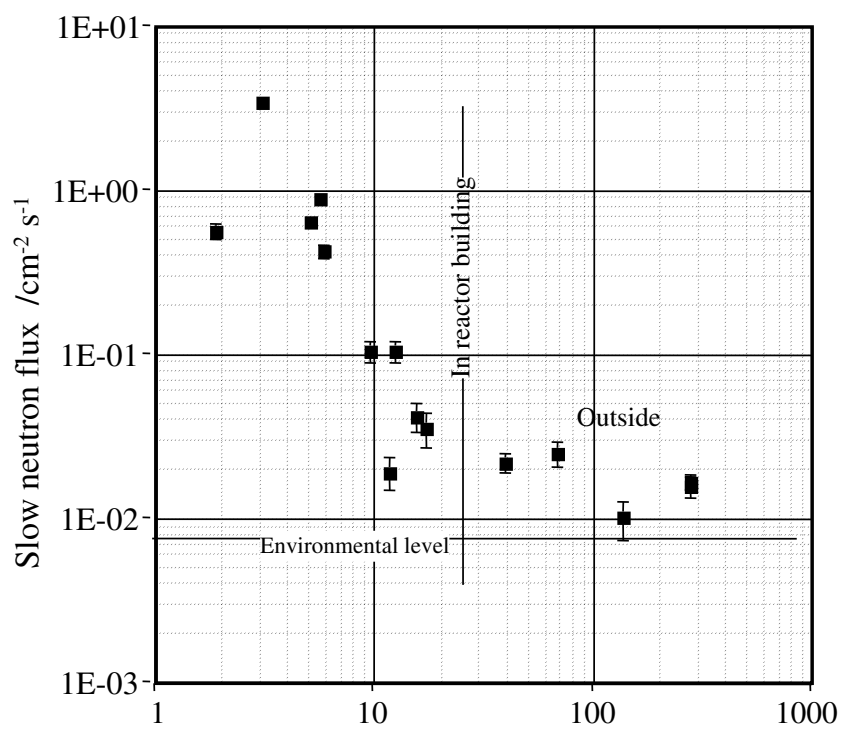

Distance from the reactor core $/ \mathrm{m}$

Figure 4. Slow neutron flux inside and outside the building of UTRKinki.

level $^{3}(7.2 \pm 0.6) \times 10^{-3} \mathrm{n} \mathrm{cm}^{-2} \mathrm{~s}^{-1}$. The marked increase of the flux at $40 \mathrm{~m}$ and $70 \mathrm{~m}$ is due to that the targets which were placed inside aluminum boxes, where the production of the neutron flux is about 3 times higher than the environmental background. ${ }^{7}$ The drop of the flux at $140 \mathrm{~m}$ distance is due to the effect of much concrete buildings around the workshop station, where the target was placed. The thermal neutron flux at $283 \mathrm{~m}$ was $(16.0 \pm 1.6) \times 10^{-3} \mathrm{n} \mathrm{cm}^{-2} \mathrm{~s}^{-1}$, which is about two times higher than environmental neutron. Target 22 was exposed at the same point for one month and showed nearly the same value, $(15.4 \pm 2.6) \times 10^{-3} \mathrm{n} \mathrm{cm}^{-2} \mathrm{~s}^{-1}$. This result shows the stability of the environmental neutron flux over a long period on average. From this figure it is evident that the thermal neutron flux rapidly decreases with the increase of the distance from the reactor center. This effect is due to the interaction or absorption of the thermal neutrons with or by the air, concrete buildings and the other surrounding materials. Also the figure shows obviously that the rise of the environmental neutron flux in the environment around the reactor is caused by the diffusion of the reactor neutrons or sky shine effect.

Acknowledgement. The authors wish to express deep thanks to Dr. T. Imanaka, Associate Prof. at Kyoto University for his kind help to calculate the neutron flux using Monte Carlo code programs, also to all members of UTR-Kinki especially Prof. Morishima, UTR-Kinki, and to Mr. H. Kofuji, LLRL of Kanazawa University for their grateful help during the UTRexperiments.

\section{References}

(1) C. Chung, and C.Y. Chen, J. Geophys. Res. 102(D25), 298 (1997).

(2) C. Chung, C.Y. Chen, and C. H. Kung, Appl. Radiat. Isot. 49, 415 (1998).

(3) A. M. M. Yousef, Doctoral thesis. South Valley University, Egypt (2000).

(4) M. Yamashita, L. D. Stephens, and H. W. Patterson, J. Geophys. Res. 71, 3817 (1966).

(5) K. Komura. Proc. $9^{\text {th }}$ Intern. Symp. on Environmental Radiation, eds. T. Tsujimoto and Y. Ogawa, Tsuruga, Fukui, Japan, p.56 (1998).

(6) M. B. Emmett, MORSE Monte Carlo Radiation Transport Code System, ORNL4972 (1975).

(7) K. O'Brien, H. A. Sandmeier, G. E. Hansen, and J. E. Campbell, J. Geophys. Res. 83 , 114 (1978). 